\section{MEAN PLATELET VOLUME IN NEONATAL SEPSIS}

doi:10.1136/archdischild-2012-302724.1179

'MY Oncel, 'R Ozdemir, 'S Yurttutan, 'FE Canpolat, '0 Erdeve, 'SS Oguz, 'N Uras, 1,2U Dilmen. ' Neonatology, Zekai Tahir Burak Maternity Teaching Hospital; ${ }^{2}$ Pediatrics, Yıldırım Beyazıt University, Faculty of Medicine, Ankara, Turkey

Background and Aim The aim of this study was to investigate any changes in mean platelet volume (MPV) in patients with neonatal sepsis (NS)

Methods Consecutive newborns diagnosed with sepsis between March and July 2011 were included in the study. Subjects were stratified into two groups; proven sepsis (Group 1a) and clinical sepsis (Group 1b). The control group (Group 2) consisted of healthy newborns matched for gestational age and birth weight. Sequential measurements of white blood cell count (WBC), platelet count (PC), MPV, interleukin-6 (IL-6) and C-reactive protein (CRP) were compared between groups, and the diagnostic value of each marker for neonatal sepsis was evaluated.

Results A total of 100 patients with neonatal sepsis ( 35 with proven sepsis and 65 with clinical sepsis) and 50 healthy controls were enrolled. A comparison of markers of sepsis obtained at baseline revealed WBC, CRP, IL- 6 and MPV levels to be significantly higher in newborns with sepsis compared to healthy controls $(p=0.01,<0.001$, $<0.001$ and 0.001 , respectively). Mean baseline serum levels of CRP and MPV were significantly higher in Group 1a compared to Group $1 b(p=0.005, p=0.007$, respectively), whereas the difference between group with regards to baseline serum levels of IL- 6 and PC was statistically insignificant ( $\mathrm{p}=0.14, \mathrm{p}=0.28$, respectively).

Conclusions This is the first study to demonstrate a statistically significant difference with regard to baseline MPV values between patients with sepsis (proven or clinical) and healthy controls. We believe that MPV could be a useful marker for the diagnosis of NS.

\section{THE PREDICTIVE VALUES OF MEAN PLATELET VOLUME (MPV) IN THE DIAGNOSIS OF NEONATAL SEPSIS}

doi:10.1136/archdischild-2012-302724.1180

B Aydin, A Zenciroglu, D Dilli, S Erol, E Ozyazici, N Karadag, S Beken, N Okumus. Neonatology, Dr Sami Ulus Maternity and Children's Health and Diseases Training and Research Hospital, Ankara, Turkey

Background and Aim Researches to identify markers with high sensitivity and specificity in the diagnosis of neonatal sepsis are being held in parallel to recent advances in neonatology. In this study, we aimed to determine predictive values of MPV in the diagnosis of neonatal sepsis.

Methods All infants diagnosed with clinical sepsis according to clinical and laboratory findings were included in this prospective study. Blood samples for hemoglobin, hematocrit, number of leukocyte, absolute neutrophyl count (ANC), number of platelet, MPV, CRP, blood culture were obtained from each patient within the first 24 hours of hospitalization. Patients who have positive culture results were accepted as proven sepsis. Patients were separated into three groups as proven sepsis ( $\mathrm{n}=82$ ) (Group-1), clinical sepsis $(\mathrm{n}=64)$ (Group-2) and control group (n=142) (Group-3)

Results Group-1 CRP levels were higher $(\mathrm{p}=0.001)$ and number of platelets were lower $(p=0.001)$ compared with other two groups. Leukocyte, ANC and MPV values were significantly high in Group-1 and Group-2 compared with Group 3 and there was no difference between Group-1 and Group-2 ( $p=0.001$ ). Negative correlation was observed between MPV and platelet levels $(r=-0.24, p=0.001)$ whereas positive correlation was observed between MPV and CRP levels $(r=0.26, p=0.001)$. It was noted that for CRP- Specificity $82 \%$, sensitivity $92 \%$, negative predictive value (NPV) $83 \%$, positive predictive value (PPV) $91 \%$, and for MPV- Specificity $54 \%$, sensitivity $82 \%$, NPV 63\%, PPV 76\%.
Conclusion High serum MPV levels in addition to CRP levels may be helpful in the diagnosis of newborns suspected to have sepsis.

\section{PROCALCITONIN LEVEL AT 24 HOURS OF AGE MAY BE PREDICTIVE FOR TRANSIENT TACHYPNEA OF THE NEWBORN}

doi:10.1136/archdischild-2012-302724.1181

${ }^{1}$ A Annagür, ${ }^{2} \mathrm{H}$ Altunhan, ${ }^{3} \mathrm{R}$ Örs, ${ }^{4 i}$ Mehmetoğlu. ${ }^{1}$ Selcuk University, Selcuklu Medical Faculty, Department of Neonatology, Konya; ${ }^{2}$ Abant Izzet Baysal University, Medical Faculty, Department of Neonatology, Bolu; ${ }^{3}$ Konya University, Meram Medical Faculty, Department of Neonatology; "Konya University, Meram Medical Faculty, Department of Clinical Biochemistry, Konya, Turkey

Background The differentiation of transient tachypnea of the newborn from bacterial pneumonia presents an important diagnostic dilemma in Neonatal Intensive Care Unit.

Aim To evaluate the predictive value of procalcitonin for transient tachypnea of the newborn.

Methods Total 122 babies were included to study. All babies were term. Babies were categorized into three groups: If the baby has prominent grunting after 2. hours of age (Group 1, n=38), if grunting subsided at 2 . hours of age and baby has only tachypnea at 24 hours of age (Group 2, $n=41$ ), if respiratory distress signs minimal or absent at 24 hours of age (Group $3, n=43$ ). In all groups, procalcitonin levels were determined at birth and 24 hours of age.

Results Procalcitonin levels at birth were significantly higher in Group 1 than other groups, but there was no difference between Groups 2 and 3. Procalcitonin levels at 24 hours of age were significantly higher in Group 1 and 2 than Group 3. No difference was found between Group 1 and Group 2 at 24 hours of age. All procalcitonin values in Group 3 were significantly lower than other groups. PCT tresholds for the diagnosis of transient tachypnea of the newborn were $0.49 \mathrm{ng} / \mathrm{ml}$ at birth (sensitivity $59 \%$, specificity $51 \%$ ); and $5.88 \mathrm{ng} / \mathrm{ml}$ at $24 \mathrm{~h}$ of life (sensitivity $80.2 \%$, specificity 90.7\%).

Conclusions Serial procalcitonin measurement at birth and 24 hours of age may be helpful in differentiating between pneumonia and transient tachypnea of the newborn. Larger studies are needed to confirm our preliminary results.

\section{TOTAL OXIDATIVE STATUS, TOTAL ANTI-OXIDATIVE STATUS AND PARAOXONASE-1 LEVELS IN NEONATAL SEPSIS}

doi:10.1136/archdischild-2012-302724.1182

${ }^{1} \mathrm{~A}$ Annagür, ${ }^{2} \mathrm{H}$ Altunhan, ${ }^{3} \mathrm{M}$ Konak, ${ }^{4} \mathrm{~S}$ Kurban, ${ }^{3} \mathrm{R}$ Örs. ${ }^{1}$ Department of Neonatology, Selcuk University, Selcuklu Medical Faculty; ${ }^{2}$ Department of Neonatology, Abant lzzet Baysal University, Medical Faculty; ${ }^{3}$ Department of Neonatology; ${ }^{4}$ Department of Clinical Biochemistry, Konya University, Meram Medical Faculty, Konya, Turkey

Aim Paraoxonase-1 (PON-1) is a calcium dependent glycoprotein enzyme that is found on the high density lipoprotein (HDL) in serum. PON-1 has been shown to protect low-density lipoprotein (LDL) and high-density lipoprotein (HDL) against oxidation and can reduce oxidative stres. In sepsis increases oxidative stres and decreases HDL concentrations. The aim of this study was to evaluate oxidant/anti-oxidant status in neonatal sepsis before and after therapy and to determine whether PON-1 could be used to monitor the treatment of neonatal sepsis.

Method Thirty-five patients with neonatal sepsis and 35 healthy controls were included in the study. PON-1 activities, total oxidant status (TOS), total anti-oxidant status (TAS) groups were measured and an oxidative stres index (OSI) was calculated.

Results Plasma levels of TOS, TAS and OSI were significantly higher in patients with neonatal sepsis before therapy as compared to after treatment $(p<0.000, p<0.000$ and $p<0.000$, respectively), plasma PON-1 level was significantly lower $(p<0.000)$ 